\title{
Depression, Self-Esteem and Sociodemographic Determinants of Suicidal Ideation Among University Undergraduates
}

\author{
Abimbola A. Akanni ${ }^{1,2, *}$ and Choja A. Oduaran ${ }^{3}$ \\ ${ }^{1}$ Population and Health Research Entity, North-West University, South Africa \\ ${ }^{2}$ Department of Psychology, Obafemi Awolowo University, Ile-Ife, Nigeria \\ ${ }^{3}$ Psychology Program, North-West University (Mafikeng Campus), South Africa
}

\begin{abstract}
The study examined the direct effects and interaction effects of depression, self-esteem, age and religious affiliation on suicidal ideation. A total of 241 (Mean age=18.89; female $=52.7 \%$ ) university undergraduates in a Nigerian university that were selected through convenient sampling procedure responded to the Rosenberg Self-Esteem Scale, Beck Depression Scale (Short form) and Suicidal Ideation Questionnaire. Results of the Two-Way ANOVA revealed a between subject significant main effect of depression, $\left(F=11.27, p<.05, \eta_{p}{ }^{2}=.089\right)$ and a non-significant main effects of self-esteem, $\left(F=1.82, p>.05, \eta_{p}^{2}=.015\right)$ on suicidal ideation. The interaction effect was not found to be significant $(F=$ $\left..49, \mathrm{p}<.05, \eta_{\mathrm{p}}^{2}=.008\right)$. however, age $\left(F=8.06, \mathrm{p}<.01, \eta_{\mathrm{p}}^{2}=.064\right)$ and religious affiliation $\left(F=9.41, p<.05, \eta_{p}^{2}=.038\right)$ were also found to have significant main effects and interaction effects $\left(F=40.85, p<.01, \eta_{p}{ }^{2}=.045\right)$ on respondents' suicidal ideation. The study concluded that depression, age and religious affiliation influenced suicidal ideation among college students.
\end{abstract}

Keywords: Depression, religious affiliation, self-esteem and suicidal ideation.

\section{INTRODUCTION}

Despite the ranking by the World Happiness report of Nigeria as the $91^{\text {st }}$ out of the 156 countries, suicide and suicidal related behaviours have been on the increase. More worrisome is the fact that the case is alarming among college students. For instance, in the first lap of 2017, there were reported cases of suicide and suicidal attempts in both private and public universities in Nigeria (Aruya, 2017). Reasons for such behaviour has become a main scientific concern to both behavioural researchers and health practitioners. Although, college life is characterized with several challenges that may prone individual to many abnormal behavioural outcomes, suicidal ideation may not readily come to mind as an option to coping with such challenges. Reports indicated that researches on suicide and suicidal related behaviour is scanty (Norhayati \& Suen, 2014).

Suicidal ideation refers to thoughts that are targeted at ending one's life. Suicide and suicidal behaviours have been found to be one of the ten leading death in the global population, and the second leading cause of death among people between ages 15 and 29 globally (WHO, 2017). It has been estimated to potentially contribute a proportion greater than $2 \%$ to the world burden of disease by 2020, particularly in sub-Saharan African (Vijayakumar, Najaraj, Pirkis \& Whiteford,

*Address correspondence to this author at the Department of Psychology, Obafemi Awolowo University, lle-Ife, Nigeria;

E-mail: bimakanni@gmail.com
2005). Furthermore, the weighted prevalence rate of suicidal ideation among Nigerian samples has been put at $7.28 \%$ (Adewuya, Ola, Coker, Atilola, Zachariah, Olugbile, et al., 2016). In fact, it has been established to be responsible for 9.9 out of every 100,000 (both sexes) death in Nigeria (WHO, 2017). Studies have revealed a number of risk factors that are associated with the prevalence rate of suicidal ideation, especially among students. These include but not limited to academic difficulties, hopelessness, stress, depression (Adewuya, et al., 2016; Oladele \& Oladele, 2016) as well as anxiety and somatic symptoms (Adewuya, et al., 2016).

In addition to such factors as depression, anxiety, academic and financial difficulties (Adewuya, et al., 2016), self-esteem, age, and religious affiliation may also influence suicidal ideation among college students. Self-esteem describes an individual's subjective evaluation of their worth. It has been found to be an important predictor of some behavioural outcomes among youths (Orth \& Robbins, 2014). Manani and Sharma (2013) reported a negative correlation between self-esteem and suicidal ideation with those having low self-esteem at higher risks of suicidal attempt. Similarly, high level of self-esteem was reported to relate to low level of suicidal ideation (Singh \& Pathak, 2017). This may differ across age groups. In fact, Chung and Young (2012) reported that age significantly predicted suicidal ideation among two countries of American and Korean youths. 
Religious affiliation may also relate to suicidal behaviours. Nigeria is a highly religious country which is evident on most campuses with several religious groups. Research on the link between religion and suicide can be traced to the work of Durkheim's finding that suicidal tendencies were lower among members of the Catholics than those who were not religious (Durkheim, 1897; Colucci \& Martin, 2008; Hoffman \& Marsiglia, 2014). Therefore, this study investigated the effects of depression, self-esteem, age and religious affiliation on suicidal ideation among university undergraduate students in a Federal university in South-western Nigeria. Firstly, we proposed that depression and self-esteem will have independent and interactive effects on suicidal ideation. Secondly, age and religious affiliation will have independent and interactive effects on suicidal ideation.

\section{METHODS}

\section{Participants and Samples}

A sample of 241 (Mean age $=18.89$; female $=52.7 \%$ ) respondents participated in the study. The participants were conveniently selected among undergraduate students from the Obafemi Awolowo University, lle-Ife, Nigeria. The respondents were recruited from three faculties that enrolled for a general psychology course. The respondents' characteristics is presented in Table 1.

\section{Measures}

\section{Sociodemographic Information}

Respondents' sociodemographic characteristics that were assessed in the current study include age, gender, level of study and religious affiliation.

\section{Suicidal Ideation}

A 10-item Suicidal Ideation Scale that was designed for college students to access suicidal thoughts in the past months was used to measure suicidal ideation. It is a self-reported scale with a 5-point Likert response format questions which ranges from 1 to 5 . High score indicate high suicidal thoughts. The Cronbach alpha coefficient for this study was .72 .

\section{Self-Esteem}

Self-esteem was measured using the Rosenberg Self-esteem Scale (RSES) developed by Rosenberg (1965). It is a global measure of self-esteem that consisted 10 items with a 4-point response format ranging from 1 (strongly disagree) to 4 (strongly agree).
The psychometric properties of the scale were reported to be good by Zhao, Kong, and Wang (2012). A Cronbach alpha coefficient of .89 was reported for this study.

\section{Depression}

Participants depressive state was assessed with the Beck Depression Scale-short form. It is a self-reported 13-item scale that was derived from the original 21items scale developed by Beck (1972) that is measured on a 4-point Likert scale ranging from 0 (symptom absent) to 4 (severe symptoms). Scores on each participant are added together to obtain a global score from 0 to 63. Low and high scores represent minimal and severe depression respectively. The authors reported a high criterion validity as well as a test-retest reliability $r=.93$. An internal consistency alpha of .89 was reported for this study.

\section{Procedure}

The approval for the conduct of the study was granted by the Ethics Committee of the Faculty of Social Science, Obafemi Awolowo University, Ile-Ife, Nigeria. Informed consent was obtained through an independent person from each participant by appending their signature on the consent form. Copies of questionnaire were administered immediately after lecture from students who indicated their willingness to participate in the study after they had been informed that participants were entitled to two credit points as rewards. Out of the 300 questionnaire that were administered, 241 representing $80.3 \%$ response rate, were returned and utilized for the study.

\section{Data Analysis}

The data which were generated from respondents were subjected a Two-Way Analysis of Variance (TwoWay ANOVA) in other to investigate the influence of depression, stress, age and religious affiliation on suicidal ideation. Furthermore, Partial ETA squared was examined to establish the individual contribution of each factor. In the conduct of the analyses, depression and stress were paired together while age and religious affiliation were also grouped together.

\section{RESULTS}

The results of the $3 \times 3$ ANOVA, as presented on Table 3, revealed a between subject significant main effect of depression, $F(2,232)=11.273, p<.05, \eta_{p}^{2}=$ .089 and a non-significant main effects of self-esteem, 
Table 1: Respondents' Socio-Demographic Characteristics

\begin{tabular}{|c|c|c|c|}
\hline \multirow{2}{*}{ Variable } & & $\mathbf{n}(241)$ & Percentage \\
\hline \hline \multirow{2}{*}{ Age } & $15-19$ & 62 & 25.7 \\
\cline { 2 - 4 } & $20-24$ & 142 & 58.9 \\
\cline { 2 - 4 } & $25-29$ & 37 & 15.4 \\
\hline \multirow{2}{*}{ Gender } & Female & 127 & 52.7 \\
\cline { 2 - 4 } & Male & 114 & 47.3 \\
\cline { 2 - 4 } & Christianity & 192 & 79.7 \\
\hline
\end{tabular}

Table 2: A Two-Way Factorial ANOVA of the Effects of Depression and Self-Esteem on Suicidal Ideation

\begin{tabular}{|c|c|c|c|c|c|c|}
\hline Source & Type III Sum of Squares & df & Mean Square & F & Sig. & Partial Eta Squared \\
\hline \hline Corrected Model & $144.633^{\mathrm{a}}$ & 8 & 18.079 & 5.372 & .001 & .156 \\
\hline Intercept & 33776.412 & 1 & 33776.412 & 10036.944 & .001 & .977 \\
\hline Self-esteem & 12.242 & 2 & 6.121 & 1.819 & .165 & .015 \\
\hline Depression & 75.874 & 2 & 37.937 & 11.273 & .001 & .747 \\
\hline Depression*Self-esteem & 6.532 & 4 & 1.633 & .485 & & .008 \\
\hline Error & 780.728 & 232 & 3.365 & & & \\
\hline Total & 49288.000 & 241 & & & & \\
\hline Corrected Total & 925.361 & 240 & & & \\
\hline
\end{tabular}

a. $\mathrm{R}$ Squared $=.156$ (Adjusted R Squared $=.127$ ).

$F(2,232)=1.82, p>.05, \eta_{p}^{2}=.015$ on suicidal ideation. It further showed a non-significant interaction effects between self-esteem and depression $\mathrm{F}(4,232)=.485$, $\mathrm{p}<.05, \mathrm{\eta}_{\mathrm{p}}^{2}=.008$. The partial ETA squared of the contribution of depression to suicidal ideation implies an $89 \%$ practical significance of the effects as observed on the Table 2.

Results of the 2x3ANOVA, as presented on Table 3 , revealed a between subject significant main effects of both age, $F(2,236)=8.06, p<.01, \eta_{p}{ }^{2}=.064$ and religious affiliation $F(1,236)=9.41, p<.05, \eta_{p}^{2}=.038$ on suicidal ideation. It further showed a significant interaction effects between age and religious affiliation $\mathrm{F}(4,236)=40.85, \mathrm{p}<.01, \mathrm{\eta}_{\mathrm{p}}^{2}=.045$. The partial ETA squared implies a $45 \%$ practical significance of the effects as observed on the Table 3 .

\section{DISCUSSION AND CONCLUSION}

The aim of this study was to examine the independent and interaction effects of depression and

Table 3: A Two-Way Factorial ANOVA of the Effects of Age and Religious Affiliation on Suicidal Ideation

\begin{tabular}{|c|c|c|c|c|c|c|}
\hline Source & Type III Sum of Squares & df & Mean Square & F & Sig. & Partial Eta Squared \\
\hline \hline Corrected Model & $67.818^{\text {a }}$ & 4 & 16.954 & 4.666 & .001 & .073 \\
\hline Intercept & 11083.764 & 1 & 11083.764 & 3050.305 & .000 & .928 \\
\hline Age & 58.593 & 2 & 29.297 & 8.063 & .000 & .064 \\
\hline Rel. affiliation & 34.176 & 1 & 34.176 & 9.405 & .002 & .001 \\
\hline Age* Rel. affiliati & 40.845 & 1 & 40.845 & 11.241 & & .045 \\
\hline Error & 857.543 & 236 & 3.634 & & & \\
\hline Total & 49288.000 & 241 & & & & \\
\hline Corrected Total & 925.361 & 240 & & & & \\
\hline
\end{tabular}

a. R Squared $=.073$ (Adjusted R Squared $=.058$ ). 
self-esteem, as well as age and religious affiliation on suicidal ideation among university undergraduates in a Nigerian sample.

Findings from the study established a significant main effect of depression on suicidal ideation. It has been reported that depression constitute potential risks for suicidal thoughts among youths (Adewuya et al., 2016; Aruya, 2017). This suggests that when depression sets in, college students may think that life is not worth living and consider termination of life as an option. We also proposed that self-esteem would have a significant effect on suicidal ideation. Contrary to the proposition, self-esteem did not influence suicidal ideation. This is not totally different from previous studies that have reported negative correlation between self-esteem and suicidal ideation (see Manani, et al., 2013; Singh, et al., 2017). Individual subjective evaluation of their worth was not associated with the conclusion worthiness of live.

Sociodemographic factors as religious affiliation and age were also found to have significant individual and interaction effects on college students' suicidal ideation. On independent effect age, past study (Chung, et al., 2012) also reported that age predicted suicidal ideation among American and Korean youths. Similarly, religious affiliation was found to have a significant effect on suicidal ideation among college students. This corroborates findings of previous studies (Durkheim, 1897; Colucci \& Martin, 2008; Hoffman \& Marsiglia, 2014) that reported lower suicidal ideation among participants who were religious compared to their counterparts who were not. We further established that the interaction effect was high, however, religious contributed more to the interaction. Therefore, the current study concluded that undergraduate students who are depressed will entertain suicidal ideation than those who are not especially those students who are religious.

\section{RECOMMENDATIONS}

Based on the findings of the study, we recommend that efforts of clinical psychologists in reducing depressive symptoms are highly required and recommended. Thus, adequate facilities that will permit instant identification and treatment of depression should be provided on university campuses. Also, religious activities have been found to increase tolerance to suicidal ideation. Therefore, freedom for religious practices need to be strengthened to encourage more participation and reduce suicidal ideation among college students. Lastly, this study was conducted among university students in a federal university in Nigeria, hence, there is a need to replicate in other private and religious-owned universities so as to have a more robust data on the subject matter of this research. Similarly, further studies that will investigate the mediating effects of situational factors on the already established links between the variables in the current study may be considered.

\section{ACKNOWLEDGEMENT}

The authors will like to appreciate the efforts of Ibraheem $\mathrm{O}$. Abdulazzeez for his assistance in data collection.

\section{CONFLICT OF INTEREST}

There is no conflict of interest of any kind between the authors. The final draft was read and approved for publication by all the authors.

\section{REFERENCES}

Adewuya, A. O., Ola, B. A., Coker, O. A., Atilola, O., Zachariah, M. P., Olugbile, O. et al., (2016). Prevalence and associated factors for suicidal ideation in the Lagos State mental health survey, Nigeria. BJPsych Open, 2(6): 385-389. eCollection https://doi.org/10.1192/bjpo.bp.116.004333

Aruya, T. (2017). Nigeria and increasing rate of suicide. This Day Newspaper online; April, 21

Beck, A. T. (1972). Measuring depression: The depression inventory. In T. A. Williams, M. M. Katz, \& J. A. Shield (Eds.), Recent advances in the psychobiology of the depressive illnesses (pp. 299-302). Washington, DC: Government Printing Office.

Chung, S. S., Joung, K. H., (2012) Risk factors related to suicidal ideation and attempted suicide: comparative study of Korean and American youth. The journal of School Nursing, 28(6), 448-458. https://doi.org/10.1177/1059840512446704

Colucci, E., \& Martin, G. (2008). Religion and spirituality along the suicidal path. Suicide and Life-Threatening Behaviour, 38(2), 229-244. https://doi.org/10.1521/suli.2008.38.2.229

Durkheim, E. (1897). Suicide. New York: Free Press.

Hoffman, S. \& Marsiglia, F. F., (2014). The impact of religiosity on suicidal ideation among youth in central Mexico, Journal of Religious Health, 53:255-266.

https://doi.org/10.1007/s10943-012-9654-1

Manani, P. \& Sharma, S. (2013). Self-esteem and Suicidal ideation: A correlational study. MJER Journal of Educational Studies, Trends \& Practices, 3(1), 75-83

Norhayati, I. \& Suen, M.W.N. (2014). Psychological factors as predictors of suicidal ideation among adolescents in Malaysia. Accessed from journals.plos.org/plosone/article? $\mathrm{id}=10.1371$ /journal. pone .0110670

Oladele, A. O., \& Oladele, I. T. (2016). Depression and suicidal ideation among college students with and without learning disabilities in Nigeria. European Journal of Social \& Behavioural Science 16(2). https://doi.org/10.15405/ejsbs.187 
Omigbodun, O., Dogra, N, Esan, O., \& Adedokun, B. (2008). Prevalence and correlates of suicidal behaviour among students in Southwest Nigeria. International Journal of Social Psychiatry, 54(1), $34-46$.

https://doi.org/10.1177/0020764007078360

Orth, U., \& Robbins, R.W. (2014). The development of self-esteem. Current Directions in Psychological Science. 23(5): 381-387. https://doi.org/10.1177/0963721414547414

Rosenberg, M. (1965). Society and the adolescent self-image. Princeton, NJ: Princeton University Press. https://doi.org/10.1515/9781400876136
Singh, R. N., \& Pathak, N. (2017). Effects of Self-esteem on suicide ideation among adolescents. The International Journal of Indian Psychology, 4(4), doi: 10.25215/0404.127

Vijayakumar L, Nagaraj K, Pirkis J, Whiteford H. (2005) Suicide in developing countries 1: frequency, distribution, and association with socioeconomic indicators. Crisis, 26: 10411. https://doi.org/10.1027/0227-5910.26.3.104

World Health Organisation (2017) Suicide Data, downloaded at www.who.int/mental_health/prevention/suicide/suicidepreven tion/en/

Received on 08-11-2018

Accepted on 11-12-2018

Published on 01-02-2019

DOI: https://doi.org/10.6000/1929-7092.2019.08.10

(C) 2019 Akanni and Oduaran; Licensee Lifescience Global.

This is an open access article licensed under the terms of the Creative Commons Attribution Non-Commercial License (http://creativecommons.org/licenses/by-nc/3.0/) which permits unrestricted, non-commercial use, distribution and reproduction in any medium, provided the work is properly cited. 